\title{
OPTICAL FILTERS DESIGN USING DIELECTRIC GRATINGS WAVEGUIDES
}

\author{
João Crisóstomo Weyl A. Costa \\ Departamento de Engenharia Elétrica \\ Centro Tecnológico da UFPa \\ Caixa Postal 8619, CEP 66075-900 Belém/PA \\ E-mail : joao@guama.cg.ufpa.br
}

\author{
Attílio José Giarola \\ Faculdade de Engenharia Elétrica e de Computação \\ Universidade Estadual de Campinas (UNICAMP) \\ Caixa Postal 6101, CEP 13083-970 Campinas/SP \\ E-mail: giarola@dmo.fee.unicamp.br
}

\begin{abstract}
The propagation characteristics of dielectric grating waveguides are analyzed here. It is shown that these structures behave as filters and may have total energy transfer between scattered, transmitted and reflected signals within a small range of variation of some given parameters. This type of anomaly, in the structures considered here, is associated with mode excitation that could be guided inside the periodic layer, and is known as the resonance anomaly. The structures considered here are planar, consisting of isotropic materials, with the periodic layer having a sinusoidally or step varying dielectric constant. A rigorous modal theory, applicable to fields with TE and TM polarization, is used. An analysis of the behavior of the excited modes inside the waveguides, which are responsible for the appearance of the resonance anomalies, is presented. For the case of small dielectric constant variations in the periodic layer it is noted that the design characteristics for the occurence of total reflection may be estimated from an analysis of the behavior of waveguides with homogeneous dielectric multilayers. It is shown how to design the waveguide presenting an arbitrary number of operating points as well as how to adjust the bandwidth around these points through the waveguide geometry and the physical characteristics of the dielectrics in the various layers. It is shown, in addition, how to obtain nearly ideal filters by means of a combination of the effects of resonance and antireflection (AR).
\end{abstract}

RESUMO: As características de propagação de guias de onda com grade dielétrica são aqui analisadas. Mostra-se que essas estruturas se comportam como filtros e podem apresentar transferência total de energia entre sinais transmitidos, refletidos e espalhados, dentro de uma pequena faixa de variação de determinados parâmetros.

Publication recommended by Area Editor of Microwaves and Optoeletronics.
Esse tipo de anomalia, nas estruturas consideradas aqui, e associado a excitação de modo que pode ser guiado dentro da camada periódica e é conhecido como anomalia de ressonância. As estruturas consideradas aqui são planares, consistindo de materiais isotrópicos, com a camada periódica apresentando uma constante dielétrica variando sinusoidalmente ou em degraus. Uma teoria modal rigorosa é usada, a qual é aplicável a campos com polarização TE ou TM. É apresentada uma análise do comportamento dos modos excitados dentro dos guias, os quais são responsáveis pelo aparecimenı das anomalias de ressonância. Nota-se, para o caso de pequenas variações da constante dielétrica na camad a periódica, que as características de projeto para ocomincia de reflexāo total podem ser estimadas a partir de uma análise do comportamento de guias de onda com mulucamadas dielétricas homogêneas. Mostra-sc como projetar guias de onda apresentando um numero arbicrario de pontos de operação e também como ajustar a fauxa de passagem ao redor desses pontos, mediante escolha da gcometria do guia de onda e das características dos dicletricos nas várias camadas. É também mostrado como obier filtros, próximos de ideais, mediante a combinją̧o de efeitos de ressonância e de anti-reflexāo (AR).

Keywords: Analysis and design of optical filters, dielectric grating waveguides, multilayered structures with dielectric gratings .

\section{INTRODUCTION}

Dielectric grating waveguides with an embedded periodic dielectric layer, also known as dielectric grating waveguides, as shown in Fig. 1, are widely used in optical devices [1]. These devices use an inherent property of dielectric grating waveguides that is to cause Wood anomalies (fast variations) in the behavior of the fields of scattered modes with respect to some given parametes, 
such as, frequency and incidence angle of input signal [2].

Wang and Magnusson [3],[4], examined these waveguides using a rigorous coupled-wave analysis (RCWA) [5] for configurations with up to five dielectric layers, with at least one of them having a dielectric constant larger than the dielectric constant of the external layers ( $\varepsilon_{C_{N C}}, \varepsilon_{S_{N S}}$ ). The occurence of total transfer of transmitted to reflected energy, with the geometries examined by Wang and Magnusson [3], [4], was shown to exist within a small variation band of some given parameters. It was found that the linewidth near the occurence of a resonance anomaly may be controlled. In addition, the resonance anomaly was found to occur at different operating points when the mode polarization is of TE or TM type. The anomaly observed by Wang and Magnusson is associated with the appearance of guided modes in the grating or in any other homogeneous layer, and is known as the resonace anomaly. In more general geometries, where more than one layer may exist above and below the periodic layer $(N C, N S \neq 1)$, there is a competition for the guidance of these modes between the various dielectric layers, with a dominance of the layers with a higher value of $\varepsilon_{r}$. This fact allows a larger flexibility in the design of filters using dielectric grating waveguides. Nearly ideal filters may be obtained by combining the resonance effects due the guided modes and the antireflection effects (AR)[4]. The observed anomalies may also be explained by considering the coupling between modes scattered to the outside of the waveguide and the higher order space harmonic [2].

More general and complex structures than those considered by Wang and Magnusson [3],[4] have been analyzed [6] using a rigorous modal theory [7]. These analyses were, however, directed toward the use of the dieletric grating waveguides as dichroic surfaces in the millimeter-wave band [8]. In this frequency band the Rayleigh type of anomalies, associated with the appearance/disappearance of a given mode at a determined angle were observed, in addition to the resonance anomalies. Results have been recently published [9] showing that the formulation developed in [6] may be used also to analyze filters and other optical devices that operate with guided mode resonance anomalies.

This paper describes an extension of the results presented in [9], incorporating to the analysis the effect of loading the periodic layer. It is presented, in addition, an analysis of the behavior of the modes excited inside the waveguide, responsible for the appearance of the resonance anomalies. For small dielectric constant variations in the periodic layer, the design characteristics for total reflections may be estimated from an analysis of the behavior of waveguides with homogeneous dielectic multilayers. A procedure for the design of a waveguide with an arbitrary number of operating points is shown, as well as how to adjust the frequency bandwidth around these points by varying the waveguide geometry and the physical characteristics of the dielectrics in the various layers.

In Section II the formulation utilized for the calculation of the scattered fields and the expressions, valuable for the design of filters with dielectric grating waveguides, are presented. Numerical results are presented in Section III, showing the behavior of dielectric grating waveguides, having in mind their use as optical filters. Based on these results, the use of these filters in some optical devices is discussed. Some closing remarks are finally presented in Section IV.

\section{THEORY}

\subsection{Field Calculation}

The rigorous modal theory developed by Peng et al. [7] is applicable to bidimensional planar structures consisting of an array of dielectric multilayers with the refractive index of one of the layers varying periodically. The dielectric media are assumed isotropic and non magnetic. The fields are assumed to have a harmonic time dependence, $\exp (j \omega t)$, where $\omega$ is the angular frequency. The dielectric grating waveguide is assumed to be infinitelly long along the $y$ direction and excited by means of a unit amplitude plane wave with an angle of incidence $\theta$ with respect to the $z$ axis (Fig. 1 ). With these considerations the fields, suported by the waveguide, may be decomposed in modes with TE and TM type of polarization.

The main steps for the calculation of the propagation fields in any waveguide region are:

a) The field components are expanded in infinite modal summations. The phase constant along the direction of periodicity, $x$, in any region, known as the Floquet constant, is determined from the characteristics of the wave that excites the waveguide. For each of the $m \underline{t h}$ supported mode, it is given by

$$
\begin{aligned}
& \frac{k_{x m}}{k_{0}}=\frac{1}{k_{0}}\left(k_{x 0}+\frac{2 \pi m}{d k_{0}}\right)=n_{N C} \sin \theta+\frac{m \lambda_{0}}{d}, \\
& m=0, \pm 1, \pm 2, \ldots \ldots \ldots \ldots
\end{aligned}
$$

where $k_{0}$ and $\lambda_{0}$ are the free space wavenumber and wavelength, respectively. $k_{x 0}$ is the fundamental Floquet wavenumber, $d$ is the period of the periodically varying index of refraction and $n_{N C}$ is the refractive index of the $N C$ medium (with a dielectric constant $\varepsilon_{C_{N C}}=\left(n_{N C}\right)^{2}$ );

b) From $k_{x m}$, the phase constant along the $z$ direction, transverse to the periodicity and inside any one of the $i$ th layer, except inside the periodic layer, may be obtained as follows 


$$
\frac{\gamma_{i m}}{k_{0}}= \pm \sqrt{n_{\mathrm{i}}^{2}-\left(\frac{k_{x m}}{k_{0}}\right)^{2}} \quad i=1,2 \ldots .(N S, N C)
$$

c) The calculation of the phase constant along $z$ direction, inside the periodic layer, $\gamma_{p m}$, is done by solving an eigenvalue equation;

d) The continuity conditions are finally applied, at the boundary between the various dielectric layers, to the propagating field components transverse to $z$ direction. The amplitude of the propagating field in any dielectric layer is therefore related to the amplitude of the wave that excites the waveguide. The amplitudes of the scattered, reflected and transmitted fields may be finally obtained.

\section{Prediction of the Resonance Anomalies}

The presence of the periodic layer causes the appearance of leaky waves in the dielectric grating waveguide. As a result, the structure does not give support to guided modes $[2],[7]$. The resonance anomalies that appear in the waveguides examinated here may be associated to modes that could possibly be guided by the dielectric grating waveguide in the limit when the ondulation of the refractive index in the periodic layer would be reduced to zero. Whent $\gamma_{\text {im }}$ is real, the mth mode is excited in the ith layer and will be multiply reflected inside the layer and scattered to the other layers, where it will also be multiply reflected, if $i \neq N S, N C$. The phase composition of these waves along the $z$ direction is such that, depending on the frequency, they may combine constructively to maximize the field intensity of the reflected wave (or of the transmitted wave). As a result of this process, there is the possibility of occurring various operating points with total reflection or transmission [8].

When the variation of the dielectric constant in the grating is small, the operating points $\left(\lambda_{0}, d, \varepsilon_{i}, h_{p}, \theta\right)$, where there is occurence of anomalies, may be estimated from the propagation characteristics of planar and uniform waveguides. $\varepsilon_{i}$ is used to denote all dielectric constants $\varepsilon_{c j}$ for the layers $\mathrm{j}$ above the periodic layer and $\varepsilon_{s \ell}$ for the layers $\ell$ below the periodic layer. In this estimation process, an average dielectric constant $\left(\varepsilon_{u}\right)$ is used for the periodic region. In this case, the longitudinal phase constant, $\beta_{n}$, of a given mode, associated with the anomaly, may be aproximated by Equation (1). The resonance anomalies are therefore associated to a strong coupling between guided modes in the periodic layer and the incident plane wave [1],[3],[8].

The procedure proposed by Wang and Magnusson [3] for the estimation of the operating points of the resonance anomalies is based in these approximations and use the transverse resonance method [10]. In this case the estimation is done by solving a transcendental equation that, for both TE and TM polarizations, may be written as

$$
-j \tan \left(\gamma_{p m} h_{p}\right)=\frac{Y_{p m}^{z}\left(Y_{C m}^{z}+Y_{S m}^{z}\right)}{\left(Y_{p m}^{z}\right)^{2}+Y_{C m}^{z} Y_{S m}^{z}}
$$

where $\gamma_{p m}$ and $Y_{p m}^{z}$ represent the phase constant and the admittance, along the $z$ direction, of the mth mode propagating along the $z$ direction of the grating, respectively. $Y_{S, C_{m}}^{z}$ represent the equivalent admittances, along the $z$ direction, associated with the min mode. $Y_{C m}^{z}$ is the admittance seen from the $z=0$ plane upwards and $Y_{S m}^{z}$ from the $z=-h_{p}$ plane downwards, in Fig. 1. As a result, the loading effect may be directly accounted in (3).

Bertoni et al. [8] present a graphical procedure for the estimation of these anomalies, based in these same principles. From their graphical procedure, however, an analitical approximation may be derived for the estimation of the operating points of the resonance anomalies. While it may be less precise, this is a more convenient and faster procedure [6]. For example, for TE polarization the operating points may be estimated from.

$\lambda_{0}=\frac{2 h_{p}\left(n_{a}+m_{r} n_{N C} \sin \theta\right) d \sqrt{n_{a}^{2}-n_{N C}^{2}}}{2 h_{p} \sqrt{n_{a}^{2}-n_{N C}^{2}}+d\left(l_{m r}-1\right)\left(n_{a}-n_{\max }\right)}$

where

$n_{\text {max }}=\max \left\{n_{N S}, n_{N C}\right\}, m_{r}=. .-2,-1,0,+1,+2, \ldots$ and $l_{m r}=1,2$,. gives the order of the resonance anomaly associated with the $n \underline{t h}$ space harmonic. The total number of resoriañi anomalies is equal to the sum of $l_{m r \geq 0}$ plus $l_{m r<0}$. Note that, for normal incidence $\left(\theta=0^{\circ}\right)$, the anomalies associated with the space harmonics propagating along the $\pm x$ directions occur at the same operating point.

Expression (4) is more precise for $\mathrm{l}_{\mathrm{m}}>1$, for $\varepsilon_{S 1} \approx \varepsilon_{C l}$ and for waveguides with total thickness of the loading dielectric layers sufficiently smaller than $h_{p}$. Nevertheless, this expression allows to obtain relations for the estimation of other related parameters, such as $h_{p}, d, \theta$ and $\varepsilon_{i}$ [6]. When only one mode, the fundamental mode, is scattered to the outside of the waveguide, Expression (4) will provide an estimation of the parameters for total energy transfer from the incident wave to the fundamental, reflected or transmitted modes.

The frequency band for occurence of the observed anomalies is situated between the operation points of excitation of some higher order mode in any waveguide layer $(i=1,2 . . N C-1$ or $N S-1)$ and the cutoff condition for the propagation of more than one mode in the regions external to the waveguide. With these conditions, the operating bandwidth for the filter may be predicted as

$$
n_{\text {eff }} \geq\left|n_{N C} \sin \theta+m_{r} \frac{\lambda_{0}}{d}\right| \geq n_{m l x}, \quad m_{r}=0, \pm 1, \pm 2, \ldots .
$$


where

$$
n_{E F}=\sqrt{\varepsilon_{E F}} \text { para } \varepsilon_{E F}=\max \left\{\varepsilon_{i}\right\}, i \neq N S, N C \text { is the }
$$

effective index of refraction of the guiding layer of the mode associated with the anomaly. Note that $\varepsilon_{\text {eff }}=\max \left\{\varepsilon_{i}\right\}$, with $i \neq S_{N S}$ and $C_{N C}$.

Expressions (3),(4) and (5) may be used to estimate the operating bandwidth and the design parameters, in the condition of occurrence of an arbitrary number of anomalies, $l_{m r}$, associated with the guided modes, through the $n t h$ harmonic. These conditions are of interest in the design of various optical devices. The numerical results that follow show the utility of these expressions

\section{NUMERICAL RESULTS}

The results shown here are all valid for fields with TE type of polarization. For the purpose of comparation, waveguides similar to those analyzed by Wang and Magnusson [3],[4] were initially used. In these waveguides the dielectric constant in the periodic layer has a step type of variation with only two dielectric sections, of equal thickness, per period. More complex structures may be analyzed, allowing the study of the effect of the dielectric losses or of a more general variation of dielectric constant in the periodic layer [6]. Structures with three dielectric regions were initially used and later the effect of adding additional dielectric layers was analyzed. A discussion is presented on how to design the structure to present a given number of resonance anomalies and how to control the linewidth around these anomalies. The simulations were all done in an IBM RISC 6000 workstation, using the Mathematica software [11].

\section{A) Waveguides with an Isolated Periodic Layer.}

Fig. 2 shows the behavior of the diffraction efficiency of the transmitted and reflected signals from the waveguide of Fig. 1 when $\varepsilon_{S_{N S}}=1, \varepsilon_{C_{N C}}=2.161, \theta=0^{\circ}$ (normal incidence), $h_{p}=330 \mathrm{~nm}$ and around a resonance anomaly with a wavelength $\lambda_{0}=514.85 \mathrm{~nm}$. The dielectric constant variation in the periodic layer is of the form $\varepsilon_{p}(x)=\varepsilon_{a}\left[1+M \cos \left(\frac{2 \pi x}{d}\right)\right], \quad$ with $\varepsilon_{a}=3$ and $M=0.5$.

This waveguide is that analyzed by Wang and Magnusson [3], using a rigorous coupled-wave analysis. The response shows that the waveguide behaves as an excellent filter. The linewidth in the frequency band, where the diffraction efficiency is larger than 0.5 , is about $1 \mathrm{~nm}$. This linewidth may be controlled by various parameters one of them being the modulation index, $M$.

For $M=0.05$, the linewidth around the wavelength of naximum reflection, $\lambda_{0}=541.787 \mathrm{~nm}$, is reduced to 0.02 $\mathrm{rm}$ [3],[9]. Within the wavelength band explored in Fig.
2 , the condition (5) is obeyed and only the fundamental mode is scattered to the external regions of the waveguide.

Fig. 3 shows a variation of the diffraction efficiency of the reflected fundamental mode for various values of $\theta$, for the same geometry analyzed by Wang and Magnusson [3]. The waveguide has a step varying dielectric constant in the periodic layer. The grating characteristic cell consists os two sections, with $\varepsilon_{p i}=2.25$ and $\varepsilon_{p 2}=4$, of equal dimension. The average dielectric constant in the periodic layer is, therefore, $\varepsilon_{a}=3.125$. The remaining parameters are $\varepsilon_{C_{N C}}=\varepsilon_{S_{N S}}=2.25, h_{p}=150 \mathrm{~nm}, d_{p}=400 \mathrm{~nm}$ and $\theta$ $=0^{\circ}, 5^{\circ}, 10^{\circ}$ and $20^{\circ}$. Note, in Fig. 3, the occurence of at least one more resonance anomaly for $\theta \neq 0^{\circ}$. The reflection is not total at these points because the incident energy is divided among the various scattered modes. It is possible, therefore, to use these structures for the design of various devices, such as beam dividers, among others. This phenomenon is illustrated in Fig. 4 for the waveguide previously described, with $\theta=20^{\circ}$, where it is shown the behavior of the diffraction efficiency of the higher order first modes scattered to the regions $1(R, m=-1)$ and 3 $(T, m=-1)$. Note that, for most examined values, except those associated with the anomalies, the energy is divided among the transmitted modes (T, $m=0$ and $m=-1$ ). Note also, in Figs. 3 and 4, that, in the vicinity of the first anomaly at $\lambda \approx 450 \mathrm{~nm}$, the scattered energy is almost totally reflectd and divided among the modes ( $\mathrm{R}, m=0$ and $m=-1)$. These energy levels for the scattered higher order modes ( $R$ or $T$ ) may be increased by adjusting the waveguide geometry [6].

Fig. 5 shows the behavior of the normalized phase constant along the $z$ direction inside the periodic layer, $\left(\frac{\gamma_{p m}}{k_{0}}\right)$, for the same waveguide analyzed in Fig. 4. The negative values represent imaginary phase constants and are associated with the evanescent modes. Note from Figs. 3, 4 and 5 that each of the resonance anomalies of Figs. 3 and 4 occurs after the excitation of a new mode, along the $z$ direction, inside the grating. The multiple reflection of these modes at the interfaces to the periodic layer with the external media causes the three anomalies observed in Fig.3, for $\theta=20^{\circ}$.

Fig. 6 shows that the linewidth around the points of maximum reflection may also be controlled by selecting the dielectric constant of the layers. The results are shown for a dielectric grating waveguide with a step varying dielectric constant with $\varepsilon_{p l}=\varepsilon_{C_{N C}}=\varepsilon_{S_{N C}}=25,3.0$ and 3.5, $\varepsilon_{p 2}=4, d_{p}=400 \mathrm{~nm}, h_{p}=150 \mathrm{~nm}$, for $\theta=0^{\circ}$. Note that the linewidth is drastically reduced with a decrease of the contrast between $\varepsilon_{a}$ and $\left(\varepsilon_{S_{N S}}, \varepsilon_{C_{N C}}\right)$ similar to what was observed when the modulation index of the periodic layer was varied. This example shows how the waveguide may operate as an ajustable filter.

An interesting design geometry of these filters may be obtained when the periodic layer is adjusted to function also as an antireflective (AR) film [4]. In these designs 
$h_{p}=\left(m \lambda_{\text {res }} / 4 \sqrt{\varepsilon_{\text {eff }}}\right) ; m=2,4 . . ; \varepsilon_{\text {eff }}=\varepsilon_{a} \quad$ and $\lambda_{\text {res }}$ is the wavelength for $\left|r_{0}\right|^{2}=1$ (resonance). This wavelength may be estimated from (3) or (4) and its exact value may be found in a rigorous procedure using the theories described in References [5] and [7]. To ilustrate this application, Fig. 7 shows three waveguide designs analyzed by Wang and Magnusson [4], using a RCWA, with $\varepsilon_{P l}=4.4 ; \varepsilon_{P 2}=3.6, d_{p}=300 \mathrm{~nm}, \theta=0^{\circ}, \varepsilon_{S_{N S}}=2.31$ and for (a) $h_{p}=131 \mathrm{~nm}, \varepsilon_{C_{N C}}=2.31$ (symmetric AR design); (b) $h_{p}=125 \mathrm{~nm}, \varepsilon_{C_{N C}}=1.0$ (asymmetric design); and (c) $h_{p}=175 \mathrm{~nm}, \varepsilon_{C_{N C}}=1.0$ (asymmetric not AR design). Note in Fig. 7 that an almost symmetric response is obtained for the AR design and that, for the symmetric AR design, the diffraction efficiency of the reflected fundamental mode is negligible around the resonances. In this case, a filter with an almost ideal response may be obtained by a proper adjustment of the filter parameters.

Expressions (4) and (5) predict that an arbitrary number of maximum reflections may be obtained by adjusting the design parameters. From (4) and (5), the number $l_{m r}$ of resonance anomalies may be obtained in terms of $h_{p} / d$, as follows

$$
\begin{aligned}
& \frac{h_{p}}{d}=\frac{\left(l_{m r}-1\right)}{2} \frac{\left(\sqrt{\varepsilon_{\max }}+\sqrt{\varepsilon_{C_{N C}}} \sin \theta\right)}{\sqrt{\varepsilon_{a}-\varepsilon_{C_{N C}}}}, \text { for } m_{r}=0,-1,-2, . . \\
& \frac{h_{p}}{d}=\frac{\left(l_{m r}-1\right)}{2} \frac{\left(\sqrt{\varepsilon_{\max }}+\sqrt{\varepsilon_{C_{N C}}} \sin \theta\right)\left(\sqrt{\varepsilon_{a}}-\sqrt{\varepsilon_{\max }}\right)}{\left(\sqrt{\varepsilon_{a}}-\sqrt{\varepsilon_{\max }}-2 \sqrt{\varepsilon_{C_{N C}}} \sin \theta\right) \sqrt{\varepsilon_{a}-\varepsilon_{C_{N C}}}}, \\
& \text { for } \quad m_{r}=0,+1,+2, \ldots
\end{aligned}
$$

The number of resonance anomalies $l_{m r}$, associated to each space harmonic, varies with the incident angle $\theta$ as follows

$$
\begin{aligned}
& \theta \leq \sin ^{-1}\left[\frac{2 h_{p} \sqrt{\varepsilon_{a}-\varepsilon_{C_{N C}}}}{d\left(l_{m r}-1\right) \sqrt{\varepsilon_{C_{N C}}}}-\sqrt{\frac{\varepsilon_{\max }}{\varepsilon_{C_{N C}}}}\right], \text { for } m_{r} \leq 0 ; \\
& \theta \leq \sin ^{-1}\left[\frac{\left(\sqrt{\varepsilon_{a}}-\sqrt{\varepsilon_{\max }}\left(\frac{2 h_{p}}{d\left(l_{m r}-1\right)} 2 \sqrt{\varepsilon_{a}-\varepsilon_{\max }}-\sqrt{\varepsilon_{\max }}\right)\right.}{\sqrt{\varepsilon_{N C}}\left(\frac{2 h_{p}}{d\left(l_{n}-1\right)} 2 \sqrt{\varepsilon_{a}-\varepsilon_{\max }}+\sqrt{\varepsilon_{a}}-\sqrt{\varepsilon_{\max }}\right)}\right], \\
& \text { for } m_{r} \geq 0
\end{aligned}
$$

To demonstrate the utility for using these expressions, the parameters $h_{p} / d$ and $\theta$ of the waveguide of the symmetric $A R$ design, considered in Fig. 7, will be varied. For normal incidence, and for $1.2 \leq h_{p} / d \leq 1.8$, (6) and (7) predict three resonance anomalies. Note from (4) that, for $\theta=0^{\circ}$, the resonance anomalies for $l_{m r<0}$ occur at the same points as those for $l_{m r>0}$. The validity of these expressions may be verified in Figs. 8, 9 and 10, where the symmetric
AR design with $\varepsilon_{C_{N C}}=2.31$ was considered. In these figures the waveguide height was initially varied to $h_{p}=393 \mathrm{~nm}$, with $h_{p} / d=1.31$ and then $\theta$ was varied. Expressions (8) and (9) predict that, by maintaining $\left(h_{l} / d\right)=1.31$, the number $l_{m<<0}$ of anomalies associated with the space harmonics is equal to 3 , if $\theta \leq 7^{\circ}$ and the number $l_{m r>0}$ is equal to 3 only if $\theta \leq 0.8^{\circ}$. This means that condition (5) is no longer satisfied by the third predicted anomaly, as may be seen in Figs. 8 to 10 , for $\theta=1^{\circ}$ and $4^{\circ}$.

\section{B) Waveguide with Multilayers and a Periodic Layer}

The introduction of dielectric layers between the periodic layer and the external media perturbs the behavior of the structure. There will be a competition for guiding the modes among the various dielectrics layers. If the dielectric constants of the loading dielectric layers are larger than $\varepsilon_{a}$, or, if these layers are sufficiently thick in comparison with $h_{p}$, , then the modes excited in these layers may also generate anomalies. $1 \mathrm{l}$ is posible therefore to have the occurence of resonance due only to the guided modes in others layers [4],[6]. The bandwidth for occurence for these anomalies may be predicted from (4). The analyses that were presented in a previous work [6] consider waveguides loaded with small thickness dielectric layers. They show that, when the loading is $10 \%$ of the thickness of the periodic layer, expressions (4), (6) to (9) still apply. The results shoun by Wang and Magnusson show that it is possible to obtain optimized filter designs by adjusting the layers thicknesses in order to transform the waveguide into an antireflective surface outside the resonance.

Fig. 11 shows two designs using different layers thicknesses for the AR design, one of them with $N C=1$, $N S=3\left(\varepsilon_{C_{N C}}=1.0, \varepsilon_{S l}=4.0, \varepsilon_{S 2}=3.42 . \varepsilon_{S, 5}=2.31, h_{S l}=63\right.$ $\mathrm{nm}, h_{S 2}=68 \mathrm{~nm}, \varepsilon_{p l}=2.56, \varepsilon_{p 2}=1.0 . \varepsilon_{i:}=1.78, d=300 \mathrm{~nm}$, $h_{p}=94 \mathrm{~nm}$ and $\theta=0^{\circ}$ ) and the other with $N C=3 . N S=1$ $\left(\varepsilon_{C_{N C}}=1.0, \varepsilon_{C l}=4.0, \varepsilon_{C 2}=1.77, \varepsilon_{S_{\text {S }}}=231 . h_{C l}=63 \mathrm{~nm}\right.$, $h_{C 2}=94 \mathrm{~nm}, \varepsilon_{p l}=4.2, \varepsilon_{p 2}=2.66 . \varepsilon_{a}=3.43 . d=300 \mathrm{~nm}, h_{p}=68$ $\mathrm{nm}$ and $\theta=0^{\circ}$ ). Note that the filter response around the anomalies is almost ideal and that the anomalies occur at the same operating points, as expecled. The filter operating point may be conveniently adjusted, still keeping a similar response [4].

Fig. 12 shows the behavior of the normalized phase constant along the $z$ direction, inside the periodic layer, for the waveguides considered in Fig. 11. Note that for the design with $N C=1, N S=3$ only the fundamental mode propagates inside the the periodic layer. The higher order modes $( \pm 1)$ are excited in the layer with $\varepsilon_{S 1}$, for $\lambda_{0} \leq 600$ $n m$ (not shown in Fig. 12), indicating that this is the layer responsible for the anomaly. In the design with $N C=3$, $N S=1$, however, note that the higher order modes excited in periodic layer are the ones that cause anomaly. These are important informations for the filter design. For example, if there is a need to increase the number of 
resonance anomalies, this may be accomplished by varying the dielectric layer thickness. In this case the parameters of the layer with dielectric constant $\varepsilon_{S I}$ should be considered in the first design and those from the periodic layer in the second design. The extent of variations of the design parameters may also be estimated using expressions (6) to (9), by considering the parameters of the guiding layer, that is, by making $\varepsilon_{a}=\varepsilon_{e f f} ; h_{p}=h_{e f f}$. This may be confirmed in Fig. 13. that shows the same waveguide considered in the design with $. Y C=1,15=3.6 y$ considering a thickness of $189 \mathrm{~nm}$ for the laye $\ldots \ldots-\ldots$ $h_{\text {eff }}(d=0.63)$. Two resonance anomalies are ctsar. 3 : 3 ! using expressions (6) and (7), the numize:

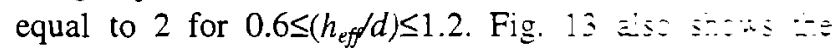
response of the filter considered in Fig. : $1 . \quad \therefore:=$ These effects have already been analyzed in F for waveguides with an isolated periodic layer. ar. $\therefore$ : confirm the convenience of using (8) and (9). It ma be concluded, from these observations and with the $7=$ ? Figs. 5 and 12, that an increase of the incident angle ma? cause a better decoupling of the anomalies due to the excited higher order modes.

\section{CONCLUSIONS}

Optical filters, consisting of dielectric grating waveguides, were analyzed here using a rigorous theory. For smal] dielectric constant variations in the periodic layer, the design characteristics for occurence of total reflection were estimated from an analysis of the behavior of homogeneous dielectric multilayer waveguides. The design of the dielectric grating waveguide, to present a given number of operating points was shown, as well as how to adjust the linewidth around these points, by varying the geometry and the physical parameters of the dielectrics in the various layers. In addition, it has been shown how to optimize the filter designs by adjusting the various layers thicknesses, with a combination of resonance and antireflection effects.

\section{ACKNOWLEDGEMENTS}

This work was partially supported by the following Brazilian agencies : CNPq, CAPES, TELEBRÁS and FINEP. The authors wish to express their gratitude to $C G$ of UFPa for the permission given to use the Mathematica software.

\section{REFERENCES}

11] T. K. Gaylord and M. G. Moharam, "Analysis and application of optical diffraction by gratings", Proc. IEEE, vol. 73, pp. 894-937, May 1985.

[2] A. Hessel and A. A. Oliner, "A New theory of Wood's anomalies on optical gratings", Appl. Optics, vol. 10, pp. 1275-1297, June 1965.

[3] S. S. Wang and R. Magnussom, "Theory and applications of guided-mode resonance filters", Appl. Optics, vol. 32, pp.. 2606-2613, May 1993.

[4] S. S. Wang and R. Magnussom, "Multilayer waveguide-grating filters", Appl. Optics, vol. 34, pp.2414-2420, May 1995.

[5] M. G. Moharam and T. K. Gaylord, "Rigorous coupled-wave analysis of planar-grating diffraction", J. Opt. Soc. Am., vol. 71, pp. 811-818, May 1981.

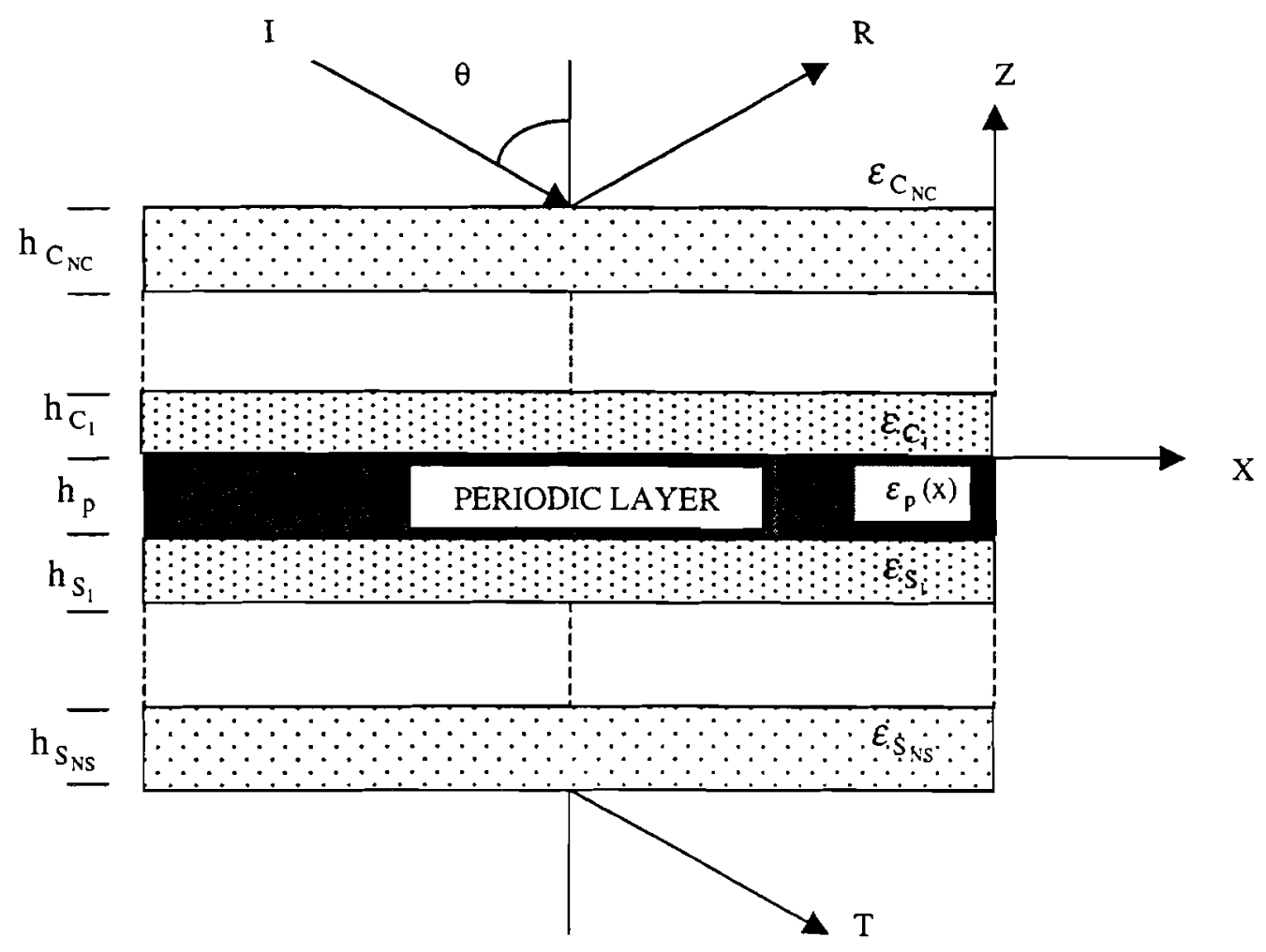

Fig. 1- Multilayer optical filter. 
resonance anomalies, this may be accomplished by varying the dielectric layer thickness. In this case the parameters of the layer with dielectric constant $\varepsilon_{S I}$ should be considered in the first design and those from the periodic layer in the second design. The extent of variations of the design parameters may also be estimated using expressions (6) to (9), by considering the parameters of the guiding layer, that is, by making $\varepsilon_{a}=\varepsilon_{e f f} ; h_{p}=h_{e f f}$. This may be confirmed in Fig. 13, that shows the same waveguide considered in the design with $N C=1, N S=3$, by considering a thickness of $189 \mathrm{~nm}$ for the layer with $\varepsilon_{S I}$ (or $h_{\text {eff }} d=0.63$ ). Two resonance anomalies are observed. By using expressions (6) and (7), the number of anomalies is equal to 2 for $0.6 \leq\left(h_{e f f} / d\right) \leq 1.2$. Fig. 13 also shows the response of the filter considered in Fig. 11, for $\theta=1^{\circ}$. These effects have already been analyzed in Figs. 8 to 10 , כr waveguides with an isolated periodic layer, and they confirm the convenience of using (8) and (9). It may also be concluded, from these observations and with the help Figs. 5 and 12, that an increase of the incident angle may cause a better decoupling of the anomalies due to the excited higher order modes.

\section{CONCLUSIONS}

Optical filters, consisting of dielectric grating waveguides, were analyzed here using a rigorous theory. For small dielectric constant variations in the periodic layer, the design characteristics for occurence of total reflection were estimated from an analysis of the behavior of homogeneous dielectric multilayer waveguides. The design of the dielectric grating waveguide, to present a given number of operating points was shown, as well as how to adjust the linewidth around these points, by varying the geometry and the physical parameters of the dielectrics in the various layers. In addition, it has been shown how to optimize the filter designs by adjusting the various layers thicknesses, with a combination of resonance and antireflection effects.

\section{ACKNOWLEDGEMENTS}

This work was partially supported by the following Brazilian agencies : CNPq, CAPES, TELEBRÁS and FINEP. The authors wish to express their gratitude to $C G$ of UFPa for the permission given to use the Mathematica software.

\section{REFERENCES}

[1] T. K. Gaylord and M. G. Moharam, "Analysis and application of optical diffraction by gratings", Proc. IEEE, vol. 73, pp. 894-937, May 1985.

[2] A. Hessel and A. A. Oliner, "A New theory of Wood's anomalies on optical gratings", Appl. Optics, vol. 10, pp. 1275-1297, June 1965.

[3] S. S. Wang and R. Magnussom, "Theory and applications of guided-mode resonance filters", Appl. Optics, vol. 32, pp.. 2606-2613, May 1993.

[4] S. S. Wang and R. Magnussom, "Multilayer waveguide-grating filters", Appl. Optics, vol. 34, pp.2414-2420, May 1995.

[5] M. G. Moharam and T. K. Gaylord, "Rigorous coupled-wave analysis of planar-grating diffraction", J. Opt. Soc. Am., vol. 71, pp. 811-818, May 1981.

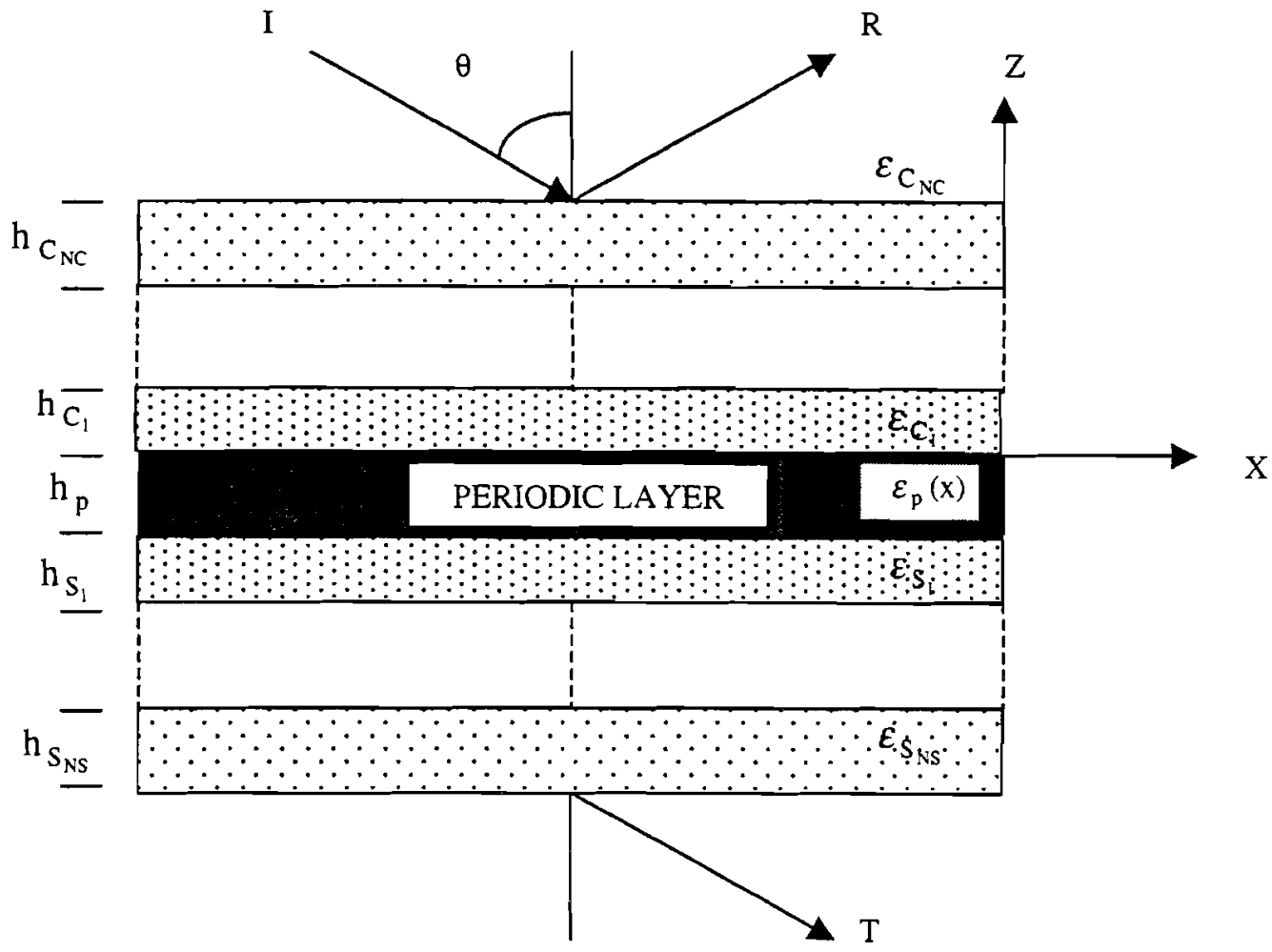

Fig. 1- Multilayer optical filter. 
[6] J. C. W. A. Costa and A. J. Giarola, "Design of dichroic structures consisting of dielectrics gratings waveguides", International Journal of Microwave and Millimeter-Wave Computer-Aided Engineering, vol. 6, No. 2, pp. 128-145, March 1996.

[7] S. T. Peng, T. Tamir and H. L. Bertoni, "Theory of periodic dielectric waveguides", IEEE Trans. Microwave Theory Tech., vol. MTT-23, pp. 123-133, Jan. 1975.

[8] H. L. Bertoni, L. S. Cheo and T. Tamir, "Frequencyselective reflection and transmission by a periodic layer", IEEE Trans. Antennas and Prop., vol. AP-37, pp. 78-83, Jan. 1989.
[9] J. C. W. A. Costa and A. J. Giarola, "Design of optica. filters using dielectric grating waveguides" (ir. Portuguese), in I3th Brazilian Telecommunication: Symposium, Águas de Lindóia, Brazil, Septembe1995, pp. 290-295.

[10] C. Balanis, Advanced Engineering Electromagnetics. New York, John Wiley, 1989.

[11] S. Wolfram, Mathematica - A System for Doing Mathematics by Computer. 2nd Ed. Addison-Wesley. 1991.

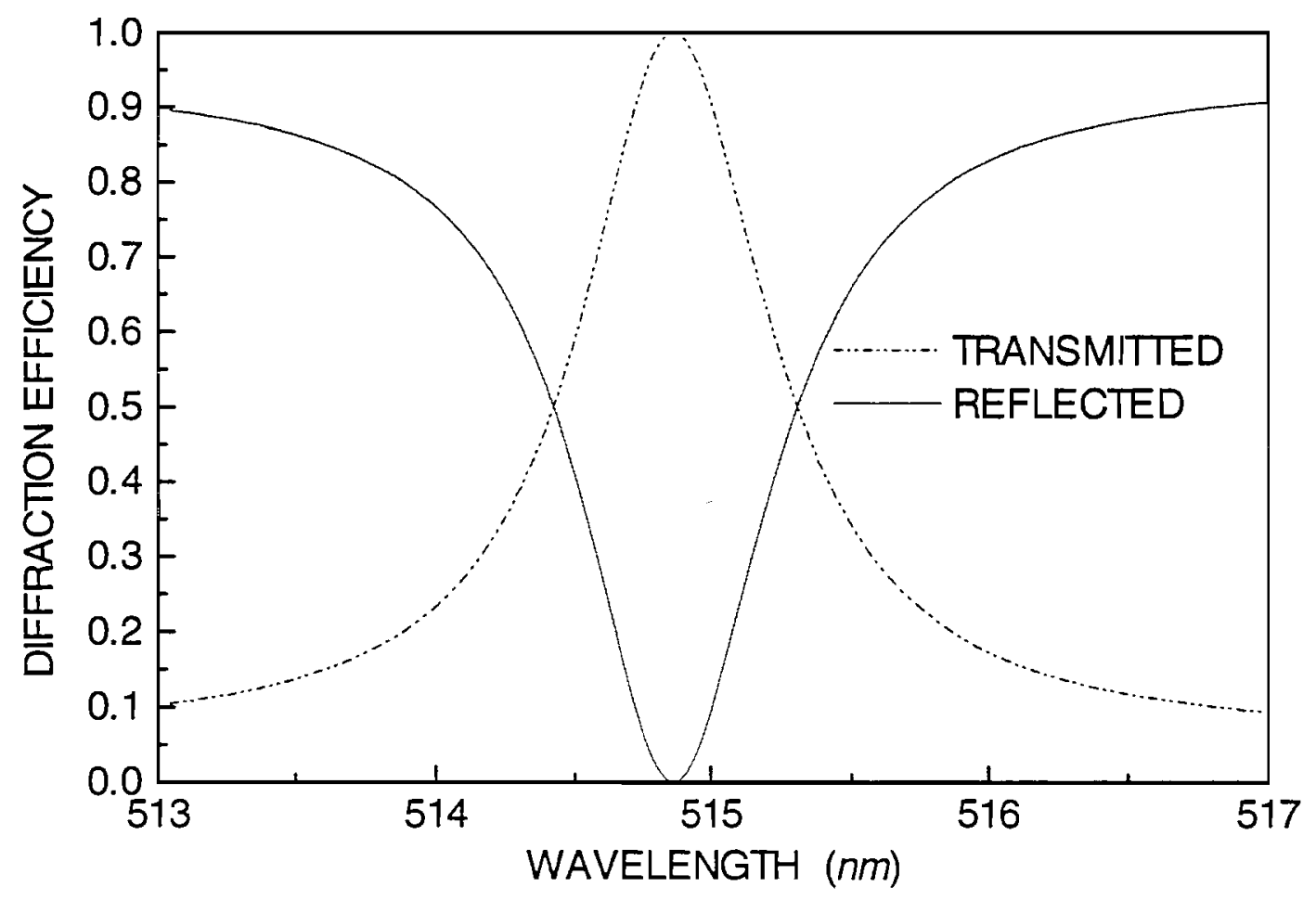

Fig. 2 - Filter response for $\theta=0^{\circ}, \varepsilon_{1}=1.0, \varepsilon_{3}=2.161 ; \varepsilon_{\mathrm{a}}=3.0, d=h_{p}=330 \mathrm{~nm}$ and $\boldsymbol{M}=\mathbf{0 . 5}$. 


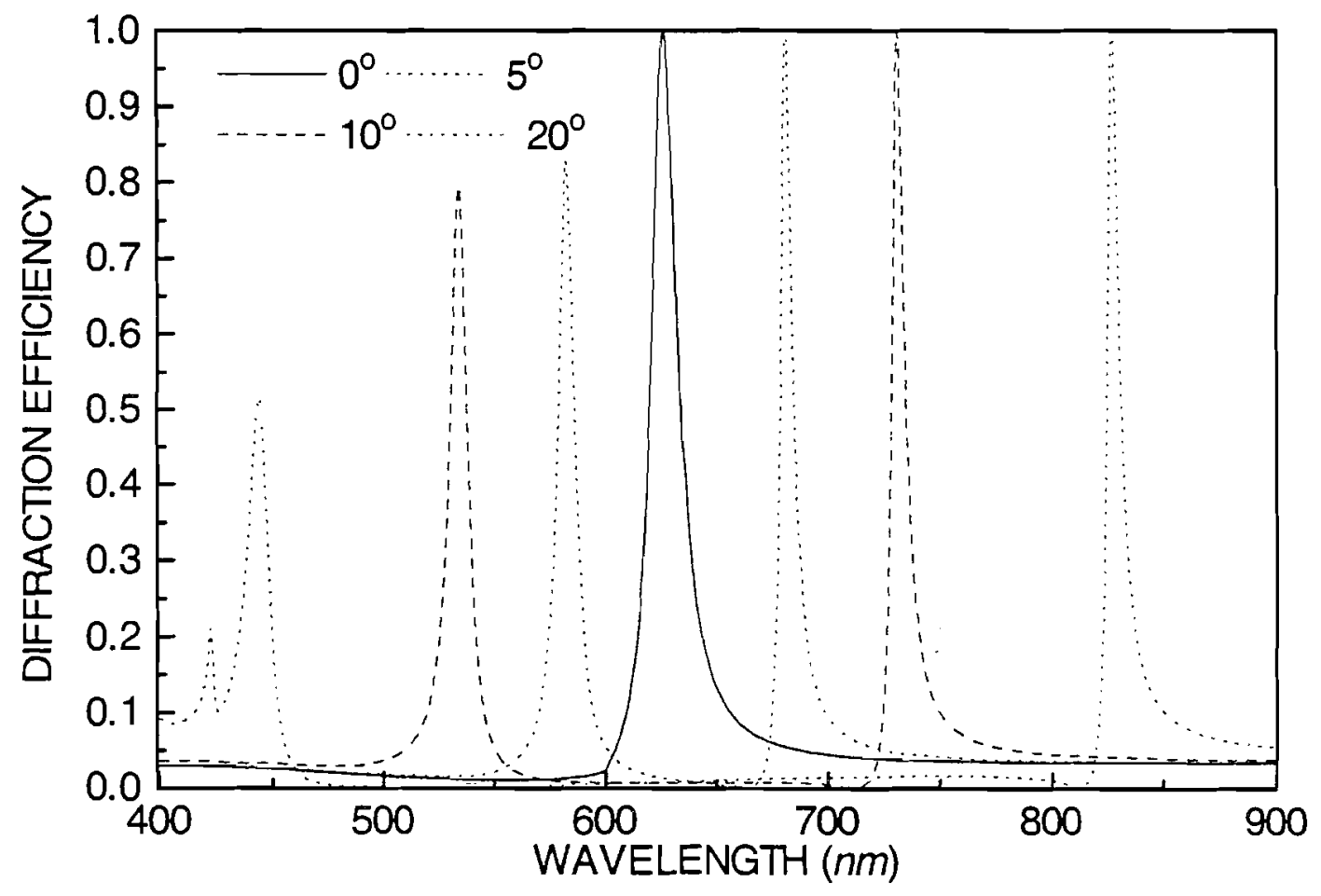

Fig. 3 - Effect of varying $\theta$ on the optical filter response.

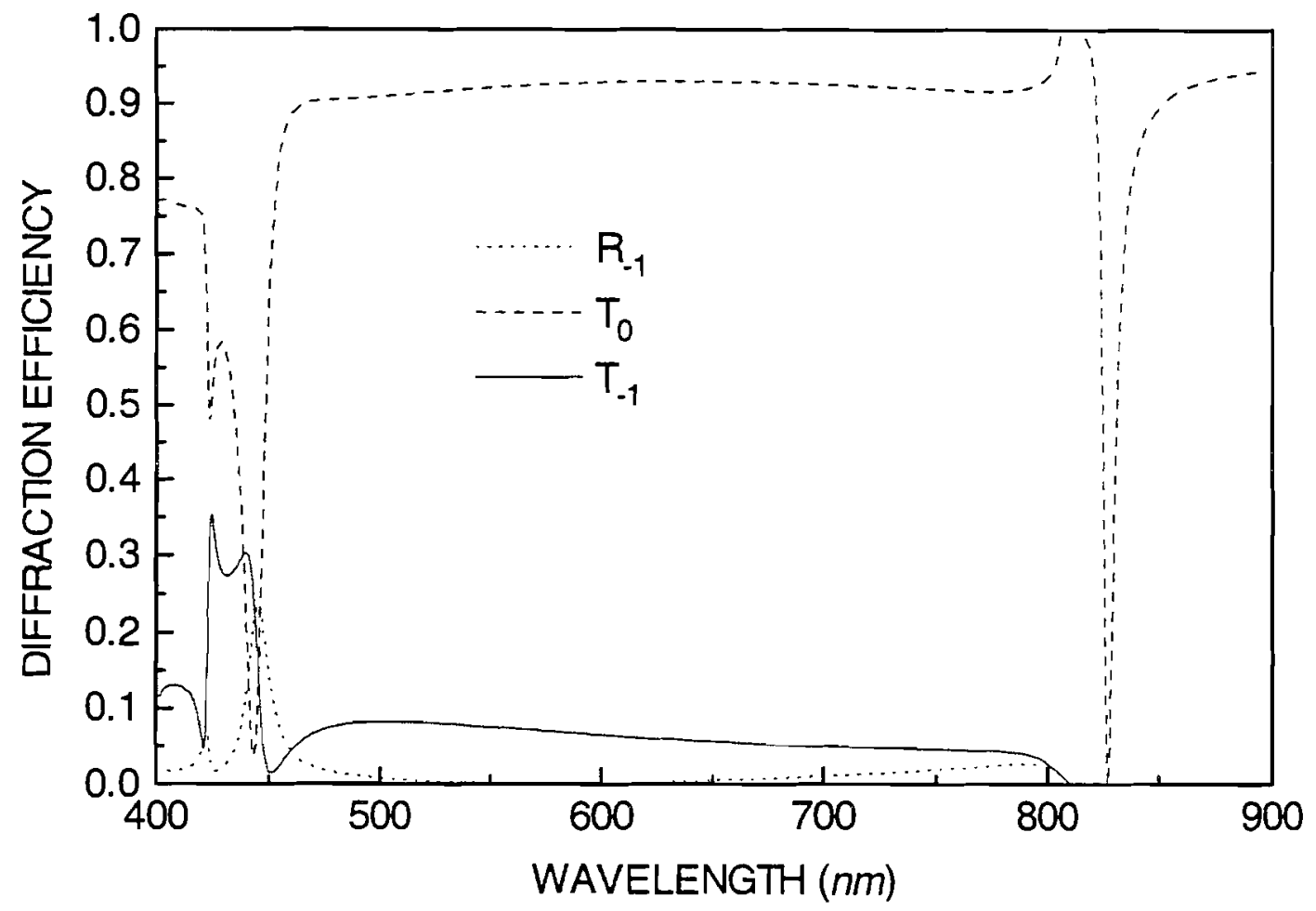

Fig. 4 - Behavior of the diffraction efficiency of the first higher order modes scattered by the filter. 


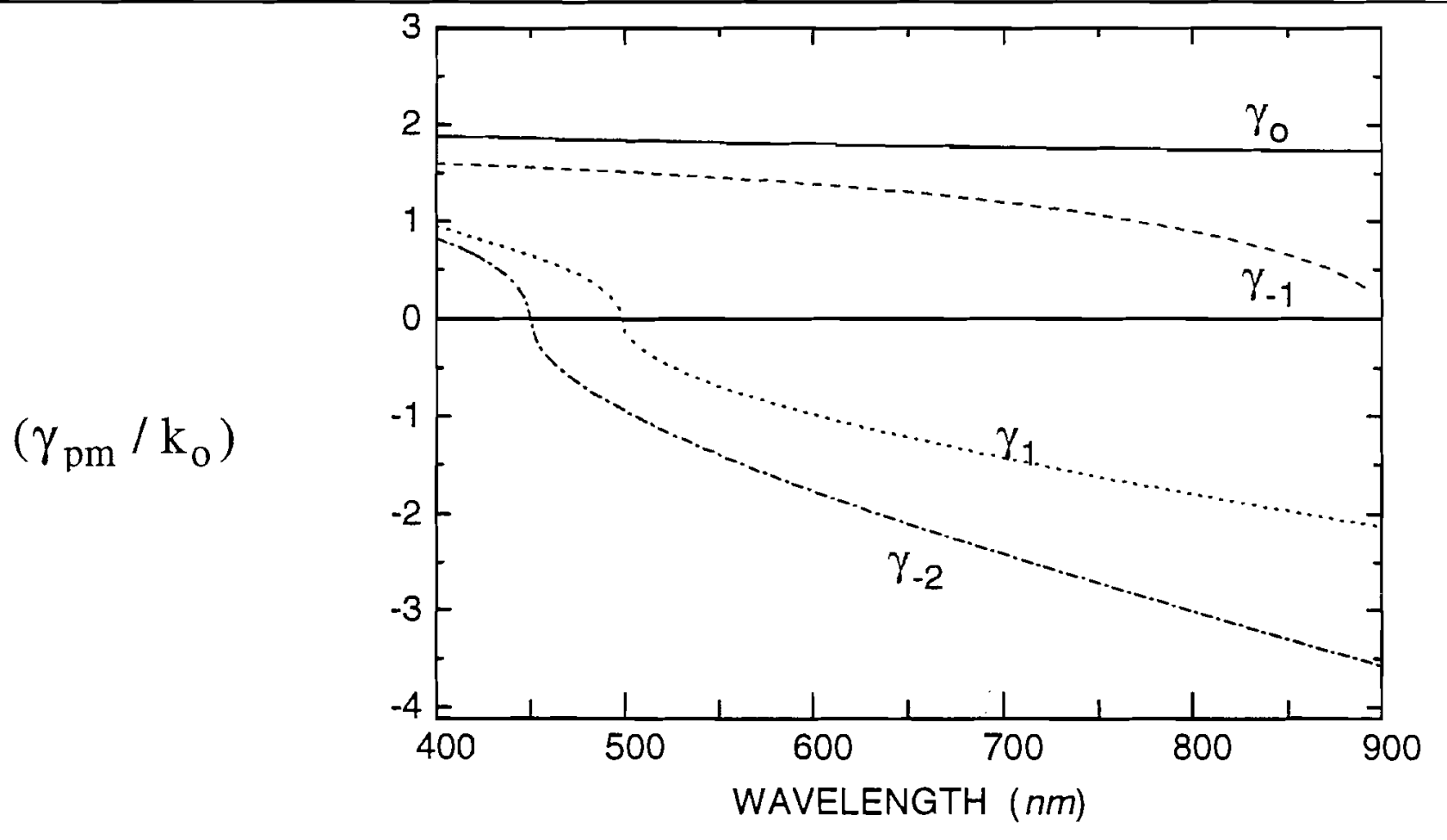

Fig. 5 - Normalized phase constant along the $z$ direction inside the periodic layer.

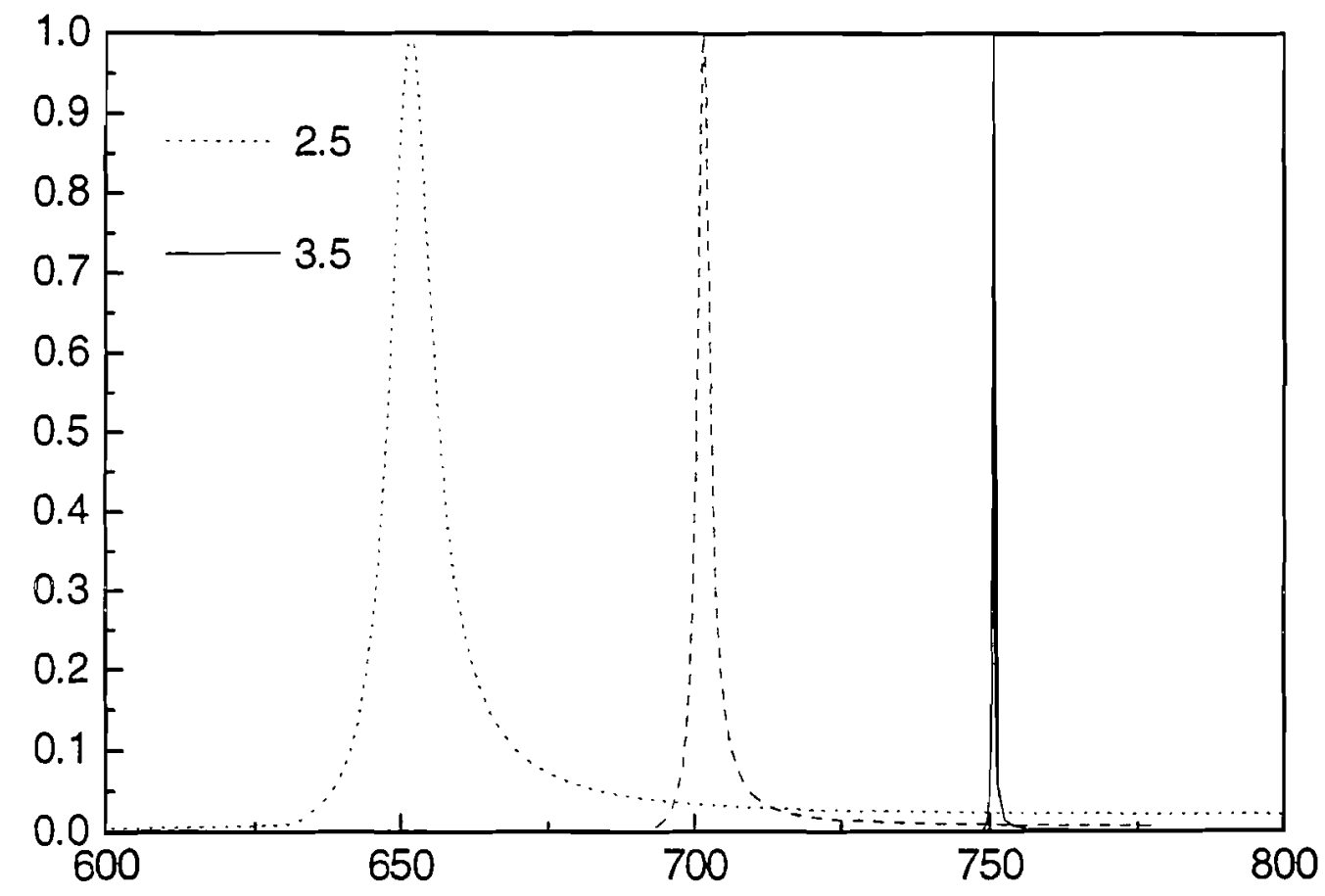

Fig. 6 - Effect of the waveguides parameters on the linewidth of the filter resonance anomalies. 


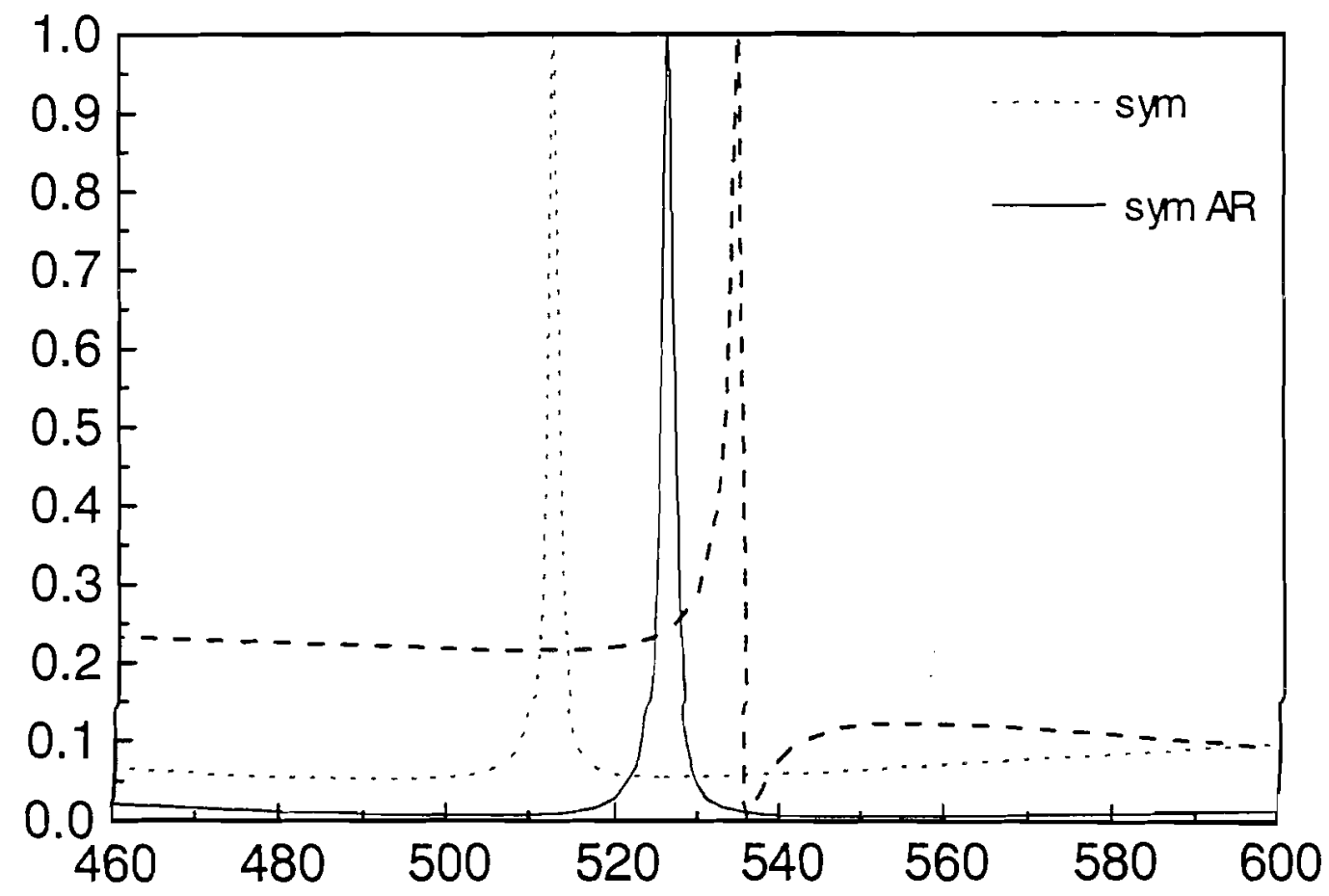

Fig. 7 - Response of filter design using symmetric and asymmetric design.

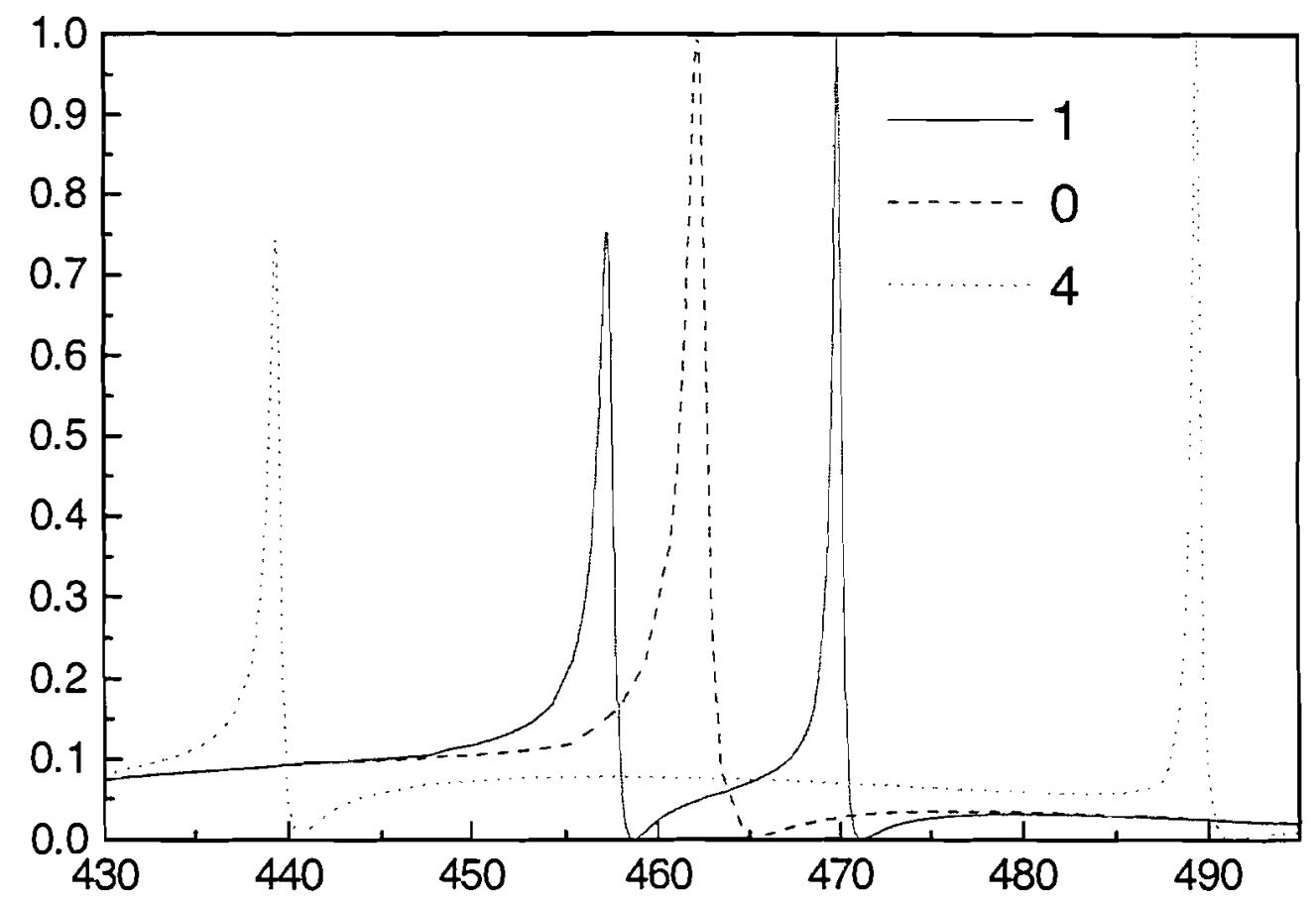

Fig. 8 - Response of filter design using symmetric $A R$, for $\theta=0^{\circ}, 1^{\circ}$ and $4^{\circ}$. 


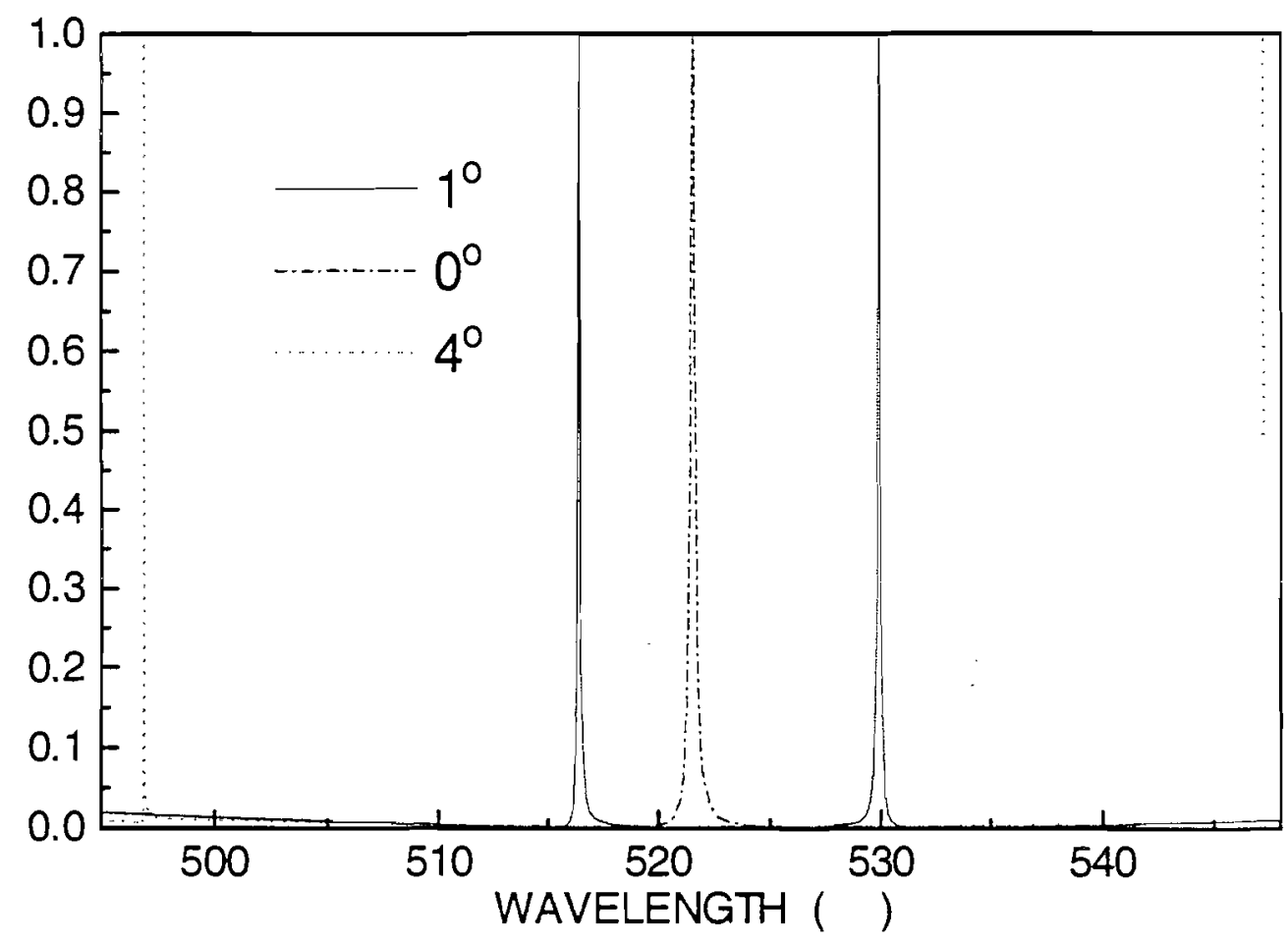

Fig. 9 - Same as in Fig. 8.

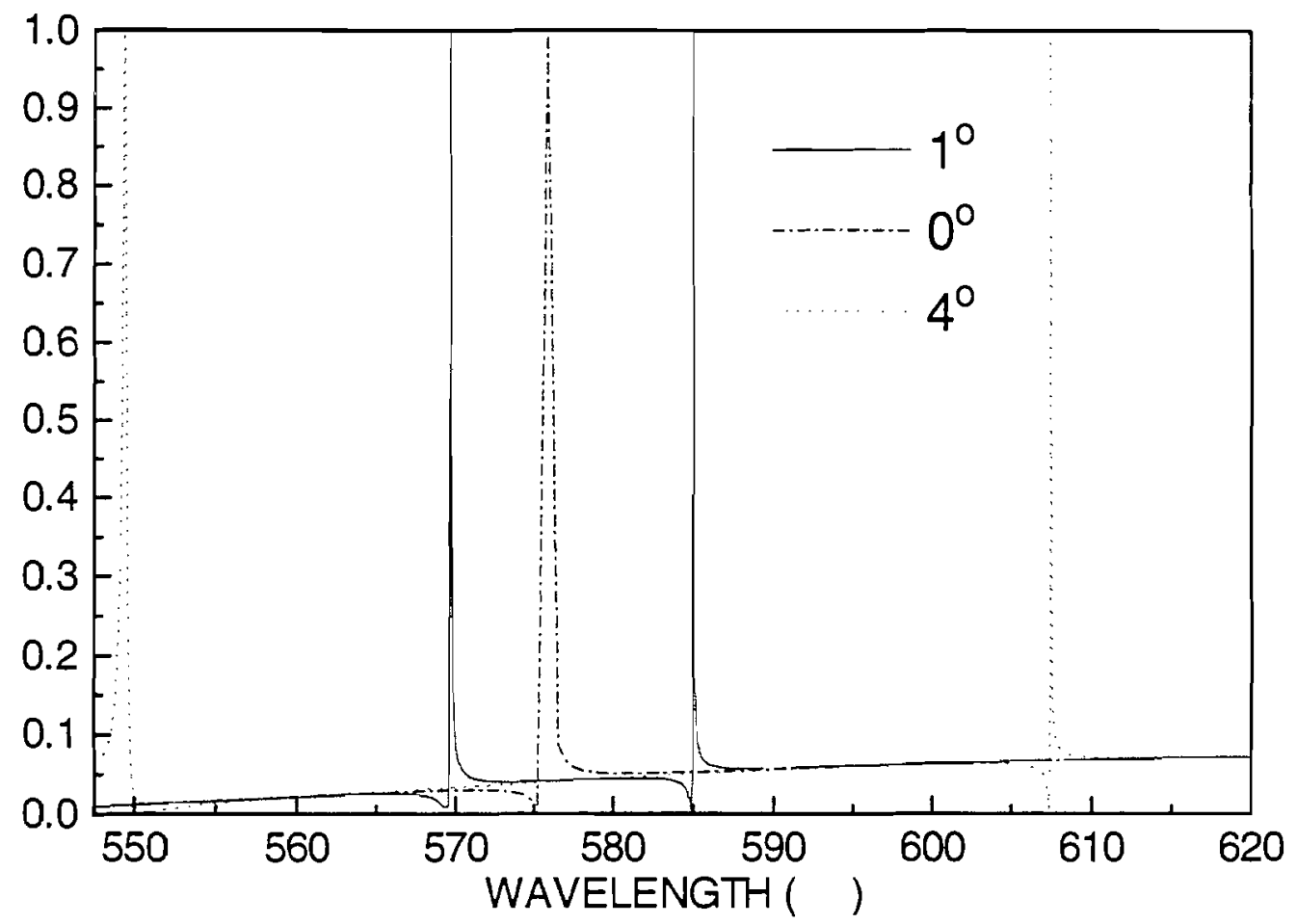

Fig. 10 - Same as in Fig. 8. 


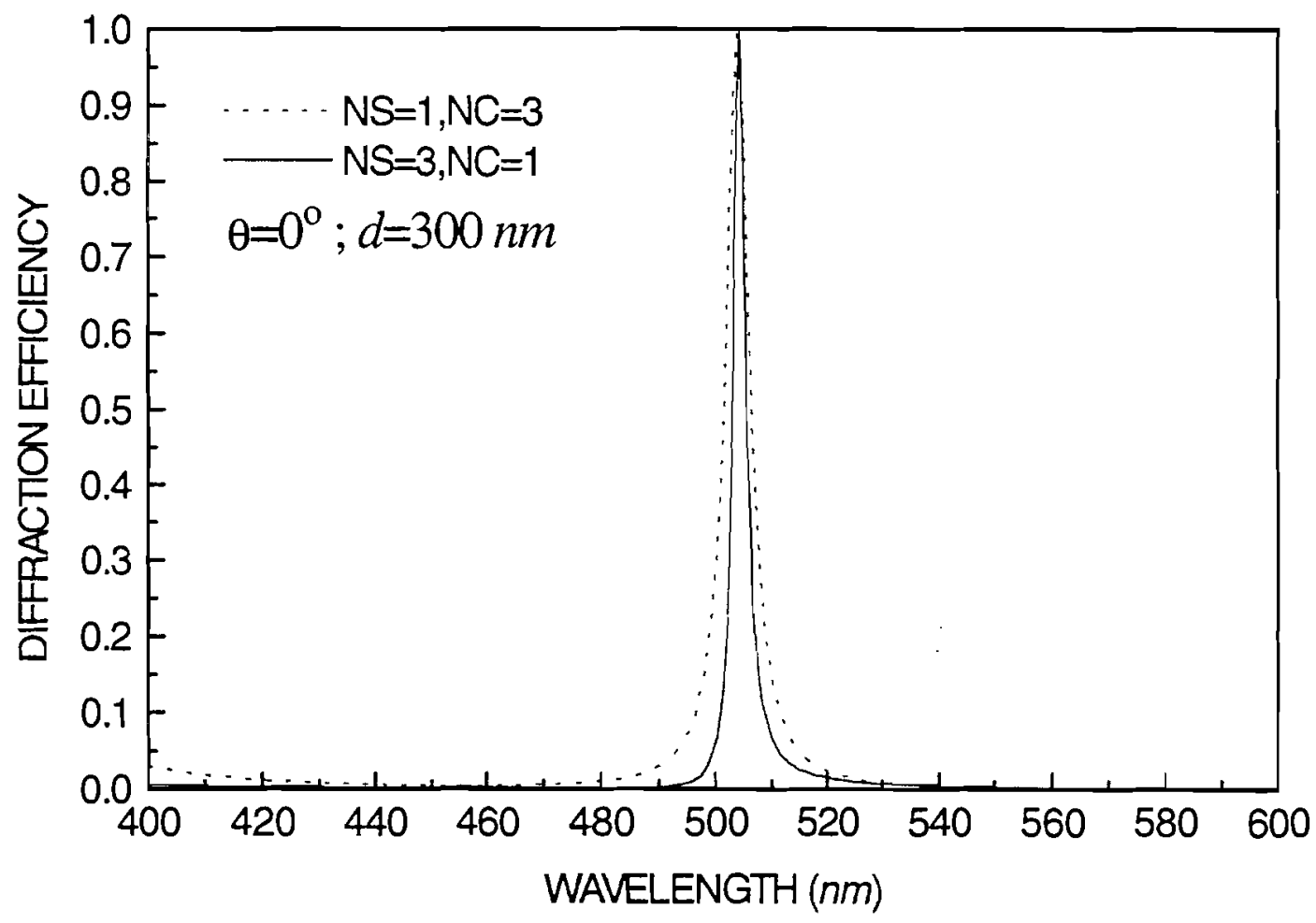

Fig .11 - Response of two filters designs using symmetric AR.

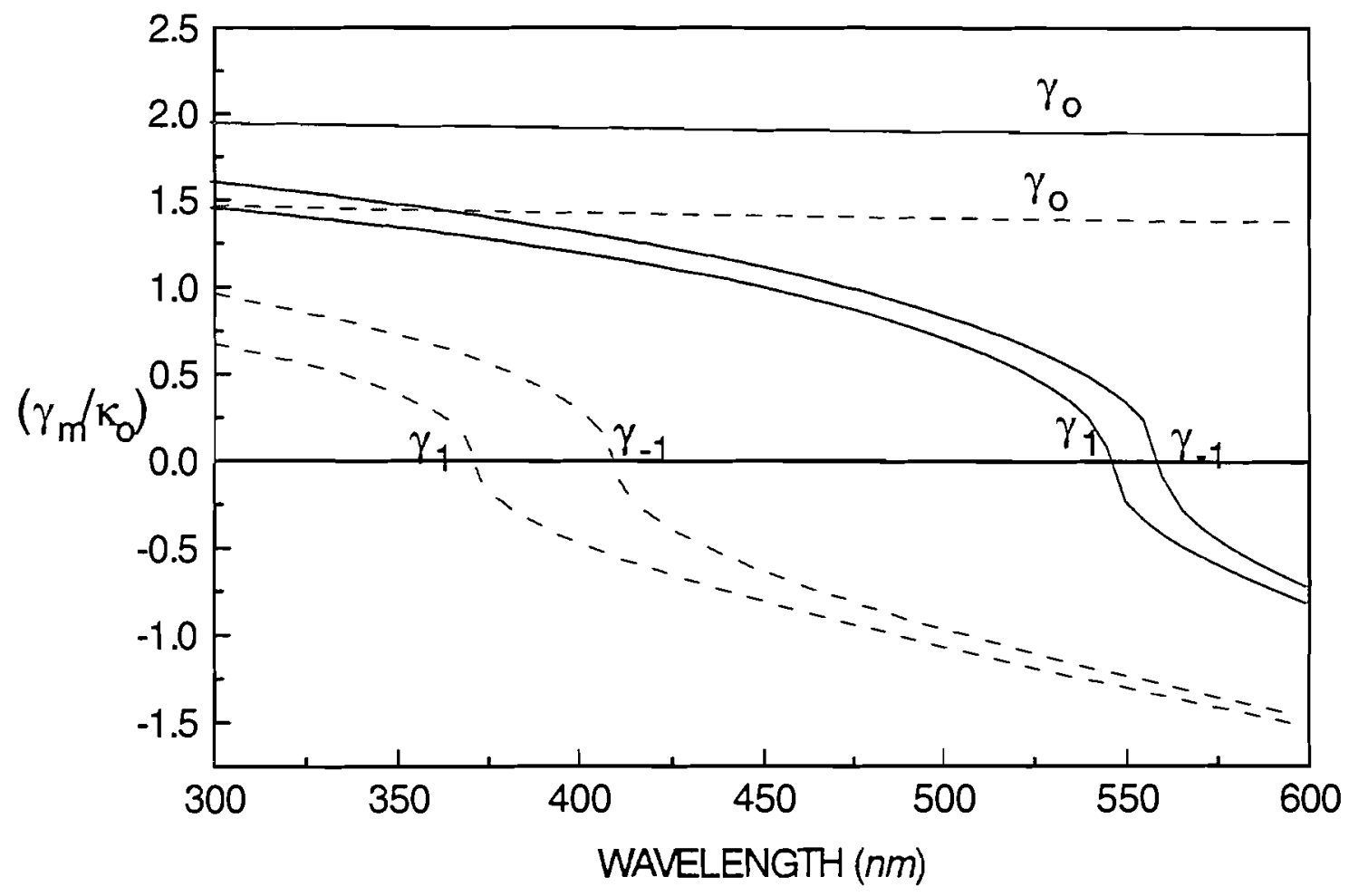

Fig .12 - Normalized phase constant behavior for the two filters designs of Fig. 11. 


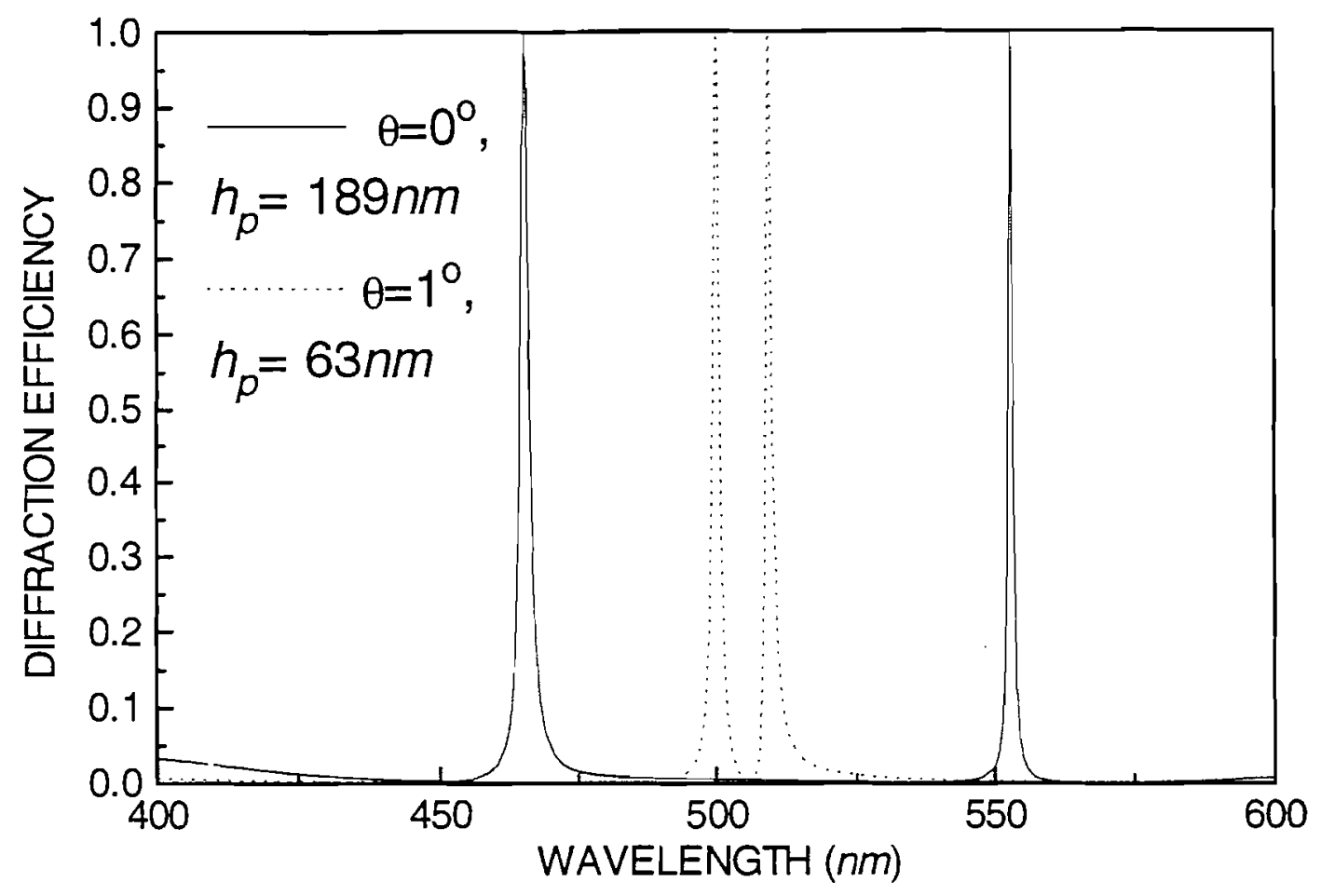

Fig. 13 - Response of three filters designs using symmetric AR.

Attílio José Giarola (M'58-SM"76 - LSM'94) was born in Brazil in 1930. He received the B.S.E.E. degree from the University of São Paulo, Brazil, in 1954, and the M.S. and Ph.D. degrees from the University of Washington, Seattle, in 1959 and 1963, respectively. Before obtaining his Ph.D. degree the taught for several years at the Instituto Tecnológico de Aeronáutica (ITA), Brazil, at Seattle University and at the University of Washington. In 1962 he joined the staff of the Boeing Company in Seattle and was responsible for research on infrared detectors and microwave devices. He was an Associated Professor of Electrical Engineering at ITA and a Visiting Professor at the University of São Paulo, Brazil. During this time he was the Program Chairman of the First National Electronics Conference in Brazil and conducted research in solid-state devices. From 1968 through 1974 he was an Associate Professor of Electrical Engineering at Texas A\&M University with responsibilities of teaching and conducting research on electromagnetics, particularly on electromagnetic susceptibility. In 1975 he joined the State University of Campinas (UNICAMP), Brazil, where he was responsible for the implantation and development of a research program in antennas, microwave and optical devices. From 1975 to 1987 Dr. Giarola was the Dean of the Graduate Studies at UNICAMP and from 1980 to 1982 he was the Vice-President of Academic Affairs of UNICAMP. $\mathrm{He}$ is now an Emeritus Professor at UNICAMP. He was the Vice-President and the President of the Brazilian Microwave and Optoelectronics Society (SBMO) and was the Chairmain of the 1985 (First) SBMO International Symposium. Dr. Giarola is a Life
Senior member of IEEE and a member of Eta Kappa Nu and Sigma Xi.

João Crisóstomo Weyl A. Costa was born in Bragança, PA, Brazil, on January 27, 1959. He received the B.Sc degree from Universidade Federal do Pará, Brazil, the M.Sc degree from Universidade Católica do Rio de Janeiro, Brasil , and the $\mathrm{PhD}$ degree from Universidade de Campinas, Brazil in 1981, 1990 and 1994, respectively, all in Electrical Engineering. He is currently at the Universidade Federal do Pará, Brazil. From 1982 to 1983, he worked at the National Department of Telecommunications in Fortaleza, CE, Brazil. From 1984 to 1986, he worked at Fundação de Telecomunicações do Pará in Belém, PA, Brazil. His research is currently focused on analysis of systems and devices for applications in optical and wireless communications networks. 